\title{
An Algorithm for Obtaining Optimal Compromise Solution of a Multi Objective Fuzzy Linear Programming Problem
}

\author{
P. K. De \\ Deptt.of Mathematics \\ National Institute of Technology \\ Silchar-788 010, Assam, India
}

\author{
Bharti Yadav \\ Deptt.of Mathematics \\ Krishna Institute of Engineering and \\ Technology \\ Ghaziabad- 201206, UP, India
}

\begin{abstract}
This paper proposes the method to the solution of multi objective linear programming problems in fuzzy environment. Here attention has been paid to the study of optimal compromise solution for multi objective fuzzy linear programming problems. Two algorithms have been presented to gives efficient solutions as well as an optimal compromise solution. An illustrative example is given to describe our proposed two algorithms.
\end{abstract}

\section{General Terms}

Multi-objective linear programming

\section{Keywords}

Fuzzy linear programming, Compromise solution, Interactivealgorithms

\section{INTRODUCTION}

The theory of fuzzy sets is based upon the investigation reported by L. Zadeh (Zadeh, 1965), involves a mathematical description of vague (inexact, fuzzy) elements, with the vagueness of information resulting not from the stochastic character of the system, but from the lack of uniqueness or selectivity there of . Accordingly, the answer to the question whether an element is associated with a fuzzy set will not be in the form of a YES or NO decision but it will require a carefully graded judgment of its association. The degree of association of defined elements is determined by an association function that must come within the scope of particular mathematical definitions, axioms and operational rules. Many real world problems are too complex to define in precise form. Also in many real applications it is often found that a single objective function is not sufficient to characterize the problem adequately . Fuzzy linear programming problems have an essential role in fuzzy modeling, which can formulate uncertainty in actual environment. In many real world problems, decisions are often made in the presence of multiple, conflicting objectives. Intensive investigations on multiple linear programming problem have been made. Among them Zimmermann's fuzzy programming appears to be an ideal approach for obtaining the optimal compromise solution to a multiple linear programming problem. In fuzzy decision making problems the concept of maximizing decision was proposed by Bellmann and Zadeh[1]. This concept was adopted to problems of mathematical programming by Tanaka et al[5]. Ronmelfanger[3] investigated on the fuzzy linear programming problems with several objectives and suggested an approach for interactive decision making in fuzzy environment. In this paper we discuss a mathematical model of multiobjective linear programming problem.

A mathematical model of maximum type multi-objective fuzzy linear programming can be stated as

$$
\max \mathrm{F}_{\mathrm{k}}=\sum_{i=1}^{m} \sum_{j=1}^{n} c_{i j}{ }^{k} x_{i j} \quad \mathrm{k}=1,2, \ldots \ldots \ldots, \mathrm{K}
$$

Subject to

$$
\mathrm{AX} \leq \mathrm{B} \quad \mathrm{X} \geq 0 \quad \mathrm{i}=1,2, \ldots \ldots ., \mathrm{K}
$$

Where $\mathrm{F}_{\mathrm{k}}(x)=\left\{\mathrm{F}^{1}(x), \mathrm{F}^{2}(x), \ldots \ldots \ldots \ldots, \mathrm{F}^{\mathrm{k}}(x)\right\}$ is a vector of $\mathrm{K}$ objective function and the superscript on both $\mathrm{F}^{\mathrm{k}}(x)$ and $\mathrm{c}_{\mathrm{ij}}{ }^{k}$ are used to identify the number of objective functions $(\mathrm{k}=1,2, \ldots$ 


\section{Definition 1.1}

An ideal solution to the multiobjective linear programming problem would result in each objective simultaneously realizing its maximum. i.e if

$\mathrm{F}_{\mathrm{k}}^{*}=\max \mathrm{F}_{\mathrm{k}}=\max \sum_{\mathrm{i}=1}^{\mathrm{m}} \sum_{\mathrm{j}=1}^{\mathrm{n}} \mathrm{c}_{\mathrm{ij}}{ }^{k} x_{i j}$

Then the vector $\mathrm{F}^{*}=\left(\mathrm{F}_{1}^{*}, \mathrm{~F}^{*} 2, \ldots \ldots, \mathrm{F}_{l}^{*}\right)$ is an ideal solution. When there is a feasible extreme point $x^{*}$ such that $\mathrm{F}^{*}=\left(\mathrm{F}_{1}^{*}, \mathrm{~F}_{2}^{*}, \ldots \ldots . ., \mathrm{F}_{l}^{*}\right)=\mathrm{F}_{1}\left(x^{*}\right)$ the multiple objective problem has an ideal solution. This would mean that for each of the subproblems

$$
\max \mathrm{F}_{\mathrm{k}}=\sum_{i=1}^{m} \sum_{j=1}^{n} c_{i j}{ }^{k} x_{i j} \quad \mathrm{k}=1,2, \ldots \ldots \ldots ., \mathrm{K}
$$

Subject to

$$
\mathrm{AX} \leq \mathrm{B} \quad \mathrm{X} \geq 0 \quad \mathrm{i}=1,2, \ldots \ldots \ldots, \mathrm{K}
$$

There is at least one identical extreme point which optimizes every $F_{k}$. therefore a compromise solution must be obtained.

Definition 1.2

An optimal compromise solution of the multiobjective linear programming problem is a solution $\bar{x}=\left(\overline{x_{i j}}\right) \in \mathrm{X}$ which is preferred by the decision maker to all other solutions, taking into consideration all criteria contained in the multi objective function. One property required of the best compromise solution is that it is non-dominated.

A feasible solution $\hat{x}=\left\{\hat{x}_{i j}\right\} \in \mathrm{X}$ is said to be a nondominated solution of the multi-objective linear programming problem if there is no other feasible solution $x=\left\{x_{i j}\right\} \in \mathrm{X}$

\section{TWO INTERACTIVE ALGORITHMS}

Two interactive algorithms have been presented to solve general multi-objective linear programming problems. In interactive algorithmic approach, the first,generates one or more nondominated solutions and then in the second one, the decision maker is querried for tradeoff information concerning these solutions, and the problem is modified based on the decision maker's responses. These two steps are then repeated iteratively until the decision maker is satisfied with

$$
\mathrm{F}^{\prime}(x)=\sum_{k=1}^{l} \mathrm{w}_{\mathrm{k}} \mathrm{F}_{\mathrm{k}}(x)
$$

Where the $\mathrm{w}_{\mathrm{k}}$ are determined by solving the $l$ by $(l+1)$ homogeneous system of linear equations.

$$
\sum_{j=1}^{l} \mathrm{w}_{\mathrm{k}} z_{k j}-\mathrm{w}_{l+1}=0, \quad \mathrm{k}=1,2, \ldots \ldots \ldots, l
$$

Step-5 Determine the vector $x^{*}$ which optimizes equation (5) subject to (2). Since the resulting problem is a single objective linear programming problem, it can be solved by any efficient algorithm.

Step6 a) If the solution found in step-5 is the best compromise solution then STOP.

If the solution found in step-5 is not best compromise solution then add that solution to the set of non-dominated solution, delete the most preferred solution from the set and return to step- the current solution, provided a satisfactory solution exists. An interactive approach can easily be adapted to the multiobjective transportation problem.

\subsection{Algorithm 1}

Step-1 Solve the $l$ single objective subproblems i.e (optimize (4) subject to (2)) and compute the $l$ nondominated solutions of the form $\mathrm{F}_{\mathrm{k}}=\left(\mathrm{F}_{1}\left(x_{k}{ }^{*}\right), \ldots \ldots \ldots, \mathrm{F}_{l}\left(x_{k}^{*}\right)\right)$ where $x_{k}{ }^{*}$ is the optimal extreme point for the $\mathrm{k}^{\text {th }}$ subproblem.

Step-2 Identify the most preferred non-dominated solution. Step 3 a) If the decision maker is satisfied with the identified solution, STOP. step-4

b)If the decision maker is not satisfied continue with

Step4 Identify a function which passes through the $l$ current non-dominated solution vector $\mathrm{F}_{\mathrm{k}}$. This problem takes the form 


\subsection{Algorithm 2}

The multi-objective LPP can be considered as a vector maximum problem. Find the values of $L_{k}$ and $U_{k}$ for the objective function $F_{k}$.

Where $\mathrm{L}_{\mathrm{k}}=$ Aspired level of achievement for objective $\mathrm{k}$.

$\mathrm{U}_{\mathrm{k}}=$ Hightest acceptance level of achievement for objective $\mathrm{k}$.

Let $\mathrm{d}_{\mathrm{k}}=\mathrm{U}_{\mathrm{k}}-\mathrm{L}_{\mathrm{k}}=$ The degradation allowance for objective $\mathrm{k}$.

Once one aspired level and degradation for each objective have been specified, we have formed the fuzzy model. Then our objective is to transform the fuzzy model into a crisp model.

Step-1 Find the values of $U_{k}$ and $L_{k}$.

Step-2 Solve the vector maximum problem as a linear programming problem using each time only one objective(ignore all others) Step-3 Determine the corresponding values for each objective.

Step-4 For each objective function $F_{k}(x)$, find the lower bound (minimum value) $L_{k}$ and upper bound (maximum value) $U_{k}$.

Step-5 For the multiobjective linear programming problem, a membership function $\mu_{k}\left(\mathrm{~F}_{\mathrm{k}}(x)\right)$ is defined as

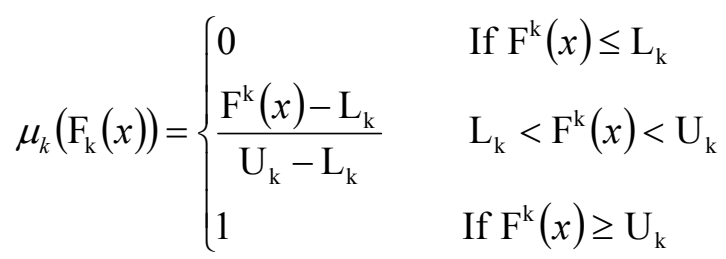

By introducing an auxiliary variable $\lambda$ equivalent conventional linear programming problem for vector maximum problem is as follows.

Now constraints (9) can be reduced to the following form

$$
\begin{aligned}
& \frac{\mathrm{F}_{\mathrm{k}}(x)-\mathrm{L}_{\mathrm{k}}}{\mathrm{U}_{\mathrm{k}}-\mathrm{L}_{\mathrm{k}}} \geq \lambda \\
& \mathrm{F}_{\mathrm{k}}(x)-\mathrm{L}_{\mathrm{k}} \geq \lambda\left(\mathrm{U}_{\mathrm{k}}-\mathrm{L}_{\mathrm{k}}\right) \\
& \mathrm{F}_{\mathrm{k}}(x) \geq \lambda\left(\mathrm{U}_{\mathrm{k}}-\mathrm{L}_{\mathrm{k}}\right)+\mathrm{L}_{\mathrm{k}} \\
& \mathrm{F}_{\mathrm{k}}(x)-\lambda\left(\mathrm{U}_{\mathrm{k}}-\mathrm{L}_{\mathrm{k}}\right) \geq \mathrm{L}_{\mathrm{k}}
\end{aligned}
$$

Step-6 Solve conventional linear programming in step-5 by using an integer programming technique to get an optimal solution and evaluate the $\mathrm{k}$ objective functions at this optimal compromise solution and then stop.

\section{NUMERICAL EXAMPLES}

Let us consider the following example of multiobjective linear programming problem(taken from [8])

$$
\begin{aligned}
& \max \left\{\mathrm{z}_{1}(x), z_{2}(x)\right\} \\
& \text { Penalities } \\
& z_{1}(x)=-x_{1}+2 x_{2} \\
& \mathrm{c}^{1}=[-1,2] \\
& z_{2}(x)=2 \mathrm{x}_{1}+x_{2} \\
& \mathrm{c}^{2}=[2,1] \\
& -x_{1}+3 x_{2} \leq 21 \\
& x_{1}+3 x_{2} \leq 27 \\
& 4 x_{1}+3 x_{2} \leq 45 \\
& 3 x_{1}+x_{2} \leq 30 \quad x_{1}, x_{2} \geq 0
\end{aligned}
$$

Such that

\section{Algorithm 1}

$$
\begin{aligned}
& \text { Step 1: Optimal solutions for the single objective } \quad \text { subproblems and corresponding } \\
& x^{\prime} s \text { for matrix } \mathrm{C}^{1} \text { are } x_{1}=0 \text { and } x_{2}=7 \\
& \text { with } \mathrm{F}_{1}\left(x^{*}{ }_{1}\right)=14, \mathrm{~F}_{2}\left(x_{1}^{*}\right)=7 \text { and } \sum \mathrm{F}\left(x_{1}^{*}\right)=21
\end{aligned}
$$


For matrix $\mathrm{C}^{2}$

$x_{1}=9$ and $x_{2}=3$ with $\mathrm{F}_{1}\left(x_{2}^{*}\right)=-3, \mathrm{~F}_{2}\left(x_{2}^{*}\right)=21$ and $\sum \mathrm{F}\left(x_{2}^{*}\right)=18$

The ideal solution to the problem is $\mathrm{F}_{1}=14$ and $\mathrm{F}_{2}=21$

$$
\sum \mathrm{F}\left(x^{*}\right)=35
$$

Step 2: The decision maker would identify $\mathrm{F}_{1}\left(x^{*}{ }_{1}\right)$ as the most preferred solution.

Step 3: Assume that the decision maker is not satisfied with this solution. To form the function $Z^{\prime}$, the following system of equations is solved

$$
\begin{aligned}
& 14 w_{1}+7 w_{1}-w_{3}=0 \\
& -3 w_{2}+21 w_{2}-w_{3}=0 \\
& w_{1}+w_{2}=1
\end{aligned}
$$

The third equations is added without loss of generality, so that the weights will sum to one. So solution for above syatem of equation is $w_{1}=.4615$ and $w_{2}=.5385$

Then new problem is ts to optimize the LPP with penality matrix $C^{\prime}=.4615 C^{1}+.5385 C^{2}$

Step 4: The solution vector for this problem is $(8,19)$, This solution is preferred to the solution at $x_{2}{ }^{*}$.Therefore it replaces this solution in the set of non-dominated solutions. Since the solution found in step-5 is the best compromise solution and this solution can't be improve on the earlier solution.

\section{$\underline{\text { Algorithm } 2}$}

As the first step, the solution of each single objective transportation problem is

$X_{1}=(0,7)$ and $X_{2}=(9,3)$

$\mathrm{F}_{1}\left(X_{1}\right)=14, \mathrm{~F}_{1}\left(X_{2}\right)=-3$

$F_{2}\left(X_{1}\right)=7, \quad \mathrm{~F}_{2}\left(X_{2}\right)=21$ i.e $-3 \leq \mathrm{F}_{1} \leq 14$ and $7 \leq \mathrm{F}_{2} \leq 21$

The membershipfunction of both $F_{1}(x)$ and $\mathrm{F}_{2}(x)$ are

$\mu_{1}\left(\mathrm{~F}_{1}(x)\right)=\frac{\mathrm{F}_{1}(x)+3}{17}$ and $\mu_{2}\left(\mathrm{~F}_{2}(x)\right)=\frac{\mathrm{F}_{2}(x)-7}{14}$

Now problem is written as follows

$\operatorname{Max} \lambda$

Such that

$$
\begin{aligned}
& x_{1}-2 x_{2}+17 \lambda \leq 3 \\
& 2 x_{1}+x_{2}-14 \lambda \geq 7 \\
& -x_{1}+3 x_{2} \leq 21 \\
& x_{1}+3 x_{2} \leq 27 \\
& 4 x_{1}+3 x_{2} \leq 45 \\
& 3 x_{1}+x_{2} \leq 30 \\
& x_{1}, x_{2} \geq 0
\end{aligned}
$$

After solving the problem the optimalcompromise solution $x_{1}=6$ and $x_{2}=7$ and overall satisfaction $\lambda=.65$ and the objective valuesare $\mathrm{F}_{1}\left(X^{*}\right)=8 \quad \mathrm{~F}_{2}\left(X^{*}\right)=19, \sum \mathrm{F}\left(x^{*}\right)=27$ 


\begin{tabular}{|l|c|c|}
\hline & Ideal solution & The compromise solution \\
\hline Algorithm-1 & $(14,21)$ & $(8,19)$ \\
\hline Algorithm-2 & $(14,21)$ & $(8,19)$ \\
\hline
\end{tabular}

\section{CONCLUSION}

In this paper we have designed two algorithms for finding fuzzy optimal compromise solution of a general fuzzy linear programming problem involving fuzzy variables and fuzzy resources. Our study revealed that by using this algorithms a general fuzzy linear programming can be converted to a crisp MOLPP and the final solution obtained as fuzzy number with a considerable degree of acceptance. It gives a better optimal compromise solution when increasing the number of objectives and constraints.

\section{REFERENCES}

[1] Bellman.R ,Zadeh .L.A, Decision making in a fuzzy environment, management science 17 B(4)(1970) 141164

[2] Feng,Y.J, A method using fuzzy mathematical programming to solve the vector maximum problem," Fuzzy sets and systems,9, 129-136(1983)
[3] Rommelfanger.H," Interactive decision making in fuzzy linear optimization problems,"European journal of operational research,41 210-217(1989)

[4] Sandipan.G, Chakraborty.M," multiobjective linear programming: A fuzzy approach, International journal of management and systems, vol 13, no 2 may-august 1997

[5] Tanaka.S,Okuda.H,Asai.K,'On fuzzy mathematical programming,J.cybernetics 3(1984) 37-46

[6] Ying-Yung.F," A method using fuzzy mathematics to solve vector maximum problem, Fuzzy sets and systems,9 (1983)

[7] Zimmermann,H.J," Fuzzy mathematical programming, comput. \& ops. Res.vol.10 no 4 (1983) 291-298

[8] Zimmermann,H.J," Fuzzy programming and linear programming with several objective functions, fuzzy sets and systems 1 (1978)45-55 